\title{
Costs and benefits of a
} bicycle helmet law for Germany

by

Gernot Sieg

Institute of Transport Economics Münster

Working Paper

No. 21

March 2014 
(c) Westfälische Wilhelms-Universität (WWU), Institute of Transport Economics, 2014

\section{Address}

Institut für Verkehrswissenschaft

Am Stadtgraben 9

D 48143 Münster, Germany

Telephone

+4925183-22994

Fax

$+4925183-28395$

\section{E-Mail}

verkehrswissenschaft@uni-muenster.de

\section{Website}

http://www.iv-muenster.de

All rights reserved.

Any reproduction, publication and reprint in the form of a different publication, whether printed or produced electronically, in whole or in part, is permitted only with the explicit written authorisation of the Westfälische Wilhelms-Universität, Institute of Transport Economics, or the author(s).

The views expressed in this paper do not necessarily reflect those of the Institute of Transport Economics or the WWU.

The Working Paper Series seeks to disseminate economic research work by the WWU, Institute of Transport Economics staff and visitors. Papers by researchers not affiliated with the WWU Institute of Transport Economics may also be considered for publication to the extent that they have been presented at research seminars/workshops organised by the institute.

The working papers published in the Series constitute work in progress circulated to stimulate discussion and critical comments. Views expressed represent exclusively the authors' own opinions.

The Series is managed by the Director of the Institute of Transport Economics. 


\title{
Costs and Benefits of a Bicycle Helmet Law for Germany
}

\author{
By Gernot SieG*
}

\begin{abstract}
This study presents a cost-benefit analysis of a law requiring cyclists to wear a helmet when riding a bicycle in Germany. The cost benefit-analysis takes into account the benefit of increased security when cyclists wear a helmet or use a transport mode that is less risky than cycling. The analysis also considers the cost of purchasing helmets, reduced fitness when cycling is replaced by a motorized transport mode, the discomfort of wearing helmets and environmental externalities. The benefits of a helmet law are estimated at about 0.7 of the costs. A bicycle helmet law for Germany is found to be a waste of resources.
\end{abstract}

JEL: K32; L91; R41

\section{Introduction}

Many studies show that bicycle helmets effectively reduce head injuries among cyclists. On the other hand, about 9 out of 10 cyclists in Germany do not wear a helmet. For this reason, the German federal government is aiming to ensure that significantly more cyclists wear a helmet, and some politicians are calling for a law requiring cyclists to wear a helmet.

A helmet law would affect cyclists who previously (in the Status Quo of no helmet law) only occasionally or never wear a helmet when cycling (see Figure 1). A helmet reduces the severity of injury in the event of an accident (Protection effect), but may reduce the pleasure of cycling and be a nuisance (Comfort effect). Furthermore, cyclists who do not have a helmet have to buy one (Purchase effect). Some will therefore opt for walking or another mode of transport, for example bus or car, rather than wearing and/or buying a helmet. These cyclists increase their safety by changing the nature of exposure to risk related to the traffic mode used (Exposure effect), but sacrifice the positive impact of cycling on the cardiovascular system (Health effect). Furthermore, motorized transport is noisy, pollutes the environment and fosters global warming (Environment effect).

Human beings are usually capable of behaving successfully even in complex and risky situations like traffic. However, from a social point of view, the decision to buy and use safety equipment can be distorted by externalities. Due to a comprehensive social security system in Germany, most of the expected medical costs and losses of earnings are external to a rational cyclist's decision to buy or use a helmet. Furthermore, due to sales taxes, the private purchasing costs of helmets exceed the social costs of production. Because of such externalities, even homogenous, rational individuals would not install some safety equipment even if it were efficient from a social point of view. Furthermore, many individuals regulary have problems estimating the probability of rare events occurring, such as bicycle accidents. A cost-benefit analysis can be used to identify such market

\footnotetext{
* Sieg: Westfälische Wilhelms-Universität, Institut für Verkehrswissenschaft, Am Stadtgraben 9, 48143 Münster, Germany, gernot.sieg@uni-muenster.de. Acknowledgements: The author thanks three anonymous referees, participants of the 2014 meeting of the committee for economic policy of the Verein für Socialpolitik, and Mark Stehr for helpful comments. This version: May 20, 2014.
} 

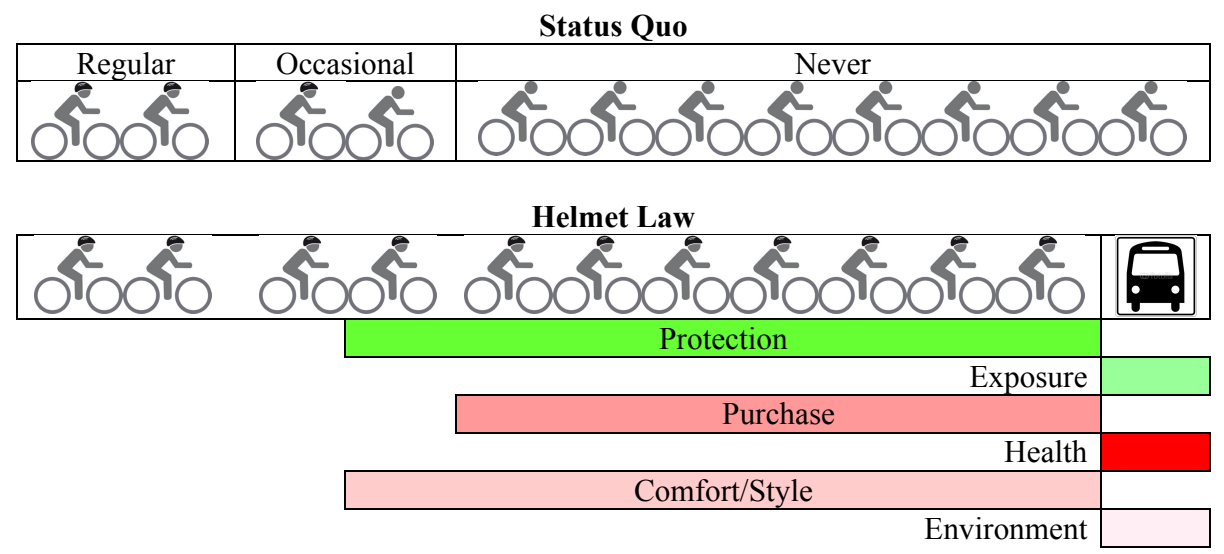

Figure 1. Negative (Red) And positive (Green) efFects of a helmet law

Figure note: The size of the effect bars is not proportional to the monetary value but indicates which cyclists are the source of the effect in question. For the monetary value see Figure 2.

failure.

From a utilitarian perspective, ${ }^{1}$ the benefits of a helmet law should at least exceed the costs. If this is not the case, resources are wasted. Empirical evidence on the costs and benefits of helmet laws is rather scarce (Taylor and Scuffham, 2002; de Jong, 2012) and there is no consensus as to whether or not helmet laws increase welfare (Robinson, 2007).

Whereas cost-benefit analysis is used regularly to determine the impact of road investment projects in Germany and many other countries, they are not used regularly to asses the impact of measures designed to improve traffic safety, arguably because some important impacts are difficult to include. However, following the seminal paper of Sælensminde (2004), many studies now include health and external cost changes when people change from travel by car to cycling or walking or vice versa. However, there has been considerable variation in how the health effects of cycling and walking are included in cost-benefit analyses (Cavill et al., 2008). The interpretation and comparison of cost benefit ratios becomes problematic and variable when some impacts, such as on the environment, climate, and health, are not valued in markets or in choice situations similar to market transactions. In order to consider the impact of cycling and walking on health this study uses the "Health economic assessment tool for cycling and walking" (HEAT) provided by the WHO Regional Office for Europe (Kahlmeier et al., 2013), enabling a sound interpretation of the results. Whereas wearing a helmet and carrying it around is obviously a nuisance, there are no market prices for this discomfort. The comprehensiveness dilemma (Sager, 2013) for the current study is that we must choose between a narrow CBA excluding the Comfort/Style aspect, and a comprehensive cost-benefit analysis, including Comfort/Style even without market-based evaluations. However, because the Comfort/Style argument is important for most cyclists who do not wear helmets, this study includes the utility losses when calculating the benefit cost ratio. Because a sensitivity analysis

\footnotetext{
${ }^{1}$ van Wee and Rietveld (2013) discuss ethical aspects of using the value of statistical life (VSL) for the ex ante evaluation of transport policy options.
} 
shows that opting for a narrow CBA, excluding the Comfort/Style aspect, does not change the policy implications, comprehensiveness is not a dilemma for this study.

The following analysis calculates the social benefits and social costs of a mandatory helmet law for Germany. The approach is similar to that of de Jong (2012) in using a simple mathematical model of individual decisions to cycle with and without a helmet law and by using parameter estimates from previous studies (see Table 1), as done by Elvik et al. (2009). However, the present study develops a more detailed model and uses more current data for Germany.

\section{Helmet law and modal split}

In 2008, all cyclists in Germany cycled a total distance of $W=3.296942 \times 10^{10}$ $\mathrm{km}$ (Bundesministerium für Verkehr, 2012), which is a annual distance of 401 $\mathrm{km}$ per head. A fraction of $q_{h}=0.13$ of this distance is cycled wearing a helmet (Bundesanstalt für Straßenwesen, 2013). The number of cyclist accident victims in 2012 in Germany was 74,776, including $F_{g}=406$ fatalities, $F_{s}=13,854$ seriously injured and $F_{l}=60,516$ slightly injured (DeStatis, 2013).

An unintended but inevitable effect of requiring a helmet when cycling is the substitution of the bicycle by other modes of transport. In principle, all nonhelmet wearer could choose not to ride a bicycle. In a survey by Rissel and Wen (2011), 22.6 per cent of the respondents answered that they would cycle more if they did not have to wear a helmet, as is required by Australian law. Of occasional cyclists, who used a bicycle in the last week, but do not cycle daily, 40.4 percent reported that they would cycle more if there were no helmet law. Robinson (1996) reports that the Australian helmet law discouraged children to the extent of 42 percent reduction in the first year, whereas the figure for adults was only 29 percent. Carpenter and Stehr (2011) analyze laws in the U.S.A. requiring youths to wear a helmet when riding a bicycle and show that the laws significantly reduced youth bicycling by $4-5$ percent. Using the results of the most current and econometrically sophisticated study from Carpenter and Stehr (2011), this present study assumes a reduction ${ }^{2} r=0.044$ of bicycling if a helmet law is passed and this reduction is accomplished entirely by previously non-helmeted cyclists. Then, after the helmet law has been passed, the total distance $\left[q_{h}+\left(1-q_{h}\right)(1-r)\right] W$ is cycled (helmeted) and only the distance $W_{\text {ind }}=\left(1-q_{h}\right) \cdot(1-r) W$ is cycled with a helmet because of the law.

People substitute a distance $W^{S}=\left(1-q_{h}\right) r W$ of cycling by other transport modes. To identify the distances travelled by these other modes, this study assumes that the travel time budget does not change. ${ }^{3}$ At a cycle speed of $v_{f}=12.3$ $\mathrm{km} / \mathrm{h}$, the annual distance of $401 \mathrm{~km}$ takes 32.6 hours to cycle. The second assumption is that the former cyclist spends his/her time budget according to the current modal split of $m s_{c}=0.31$ on cars, $m s_{b}=0.26$ on public transport and $m s_{p}=0.3$ as pedestrians (Jahn and Krey, 2010). Because these values are calculated for distances travelled (and not for time spent), we use the speeds of walking $v_{p}=4.9 \mathrm{~km} / \mathrm{h}$, of going by car $v_{c}=24.9 \mathrm{~km} / \mathrm{h}$ and of public transport $v_{b}=17.0$ $\mathrm{km} / \mathrm{h}$ to calculate how much time $t$ is spent traveling $1 \mathrm{~km}$ of distance using the

\footnotetext{
${ }^{2}$ The DDD (difference in difference in differences) estimate is -0.031 with a standard error of 0.015 (Carpenter and Stehr, 2011, Table 5), the baseline rate of cycling is estimated to $71 \%$ (Carpenter and Stehr, 2011, Table 3). The point estimate therefore is $0.031 / 0.71=4.4 \%$ with a 95 percent confidence interval of $0.2 \%$ to $8.5 \%$.

${ }^{3}$ See Mokhtarian and Chen (2004) for a discussion of travel time budgets.
} 
different transport modes according to the observed modal split:

$$
t=\frac{m s_{c} / v_{c}+m s_{b} / v_{b}+m s_{p} / v_{p}}{m s_{c}+m s_{b}+m s_{p}} .
$$

The average annual distance $w=401 \mathrm{~km}$ of cycling is substituted by

$$
w_{s}=\frac{w}{v_{f}} \frac{1}{t}=319 \mathrm{~km}
$$

and of that, $113 \mathrm{~km}$ by car, $95 \mathrm{~km}$ by public transport and $110 \mathrm{~km}$ by walking. To summarize, people substitute a distance $W^{s}=\left(1-q_{h}\right) r W$ of cycling by

$$
W_{i}^{s}=\frac{m s_{i}}{m s_{c}+m s_{b}+m s_{p}} \frac{\left(1-q_{h}\right) r W}{v_{f}} \frac{m s_{c}+m s_{b}+m s_{p}}{m s_{c} / v_{c}+m s_{b} / v_{b}+m s_{p} / v_{p}}
$$

with $i \in\{c, b, p\}$.

\section{Monetary evaluation of the effects of a helmet law}

Except for the costs of new helmets (Section 3.4) and the health effect, this study uses statistical averages that are proportional to the annual distance $W$ cycled in Germany to calculate all costs and benefits. Therefore, it is irrelevant whether effects occur because of a change in helmeted cycling or a change in the number of helmeted cyclists. Only in order to estimate the number of helmets cyclists have to buy because of the law, do we need to calculate the number of cyclists and helmet owners in Germany. ${ }^{4}$

\section{A. Protection effect}

Bicycle helmets are a passive safety measure and cannot prevent, but only reduce the consequences of accidents. In the case of an accident, head injuries are usually also associated with those of the extremities as well, the extent of which a helmet can not reduce. Richter (2005) analyzed 22,794 cyclists hospitalized as victims of traffic accidents at the "Abteilung fr Unfallforschung der Unfallchirurgischen Klinik der Medizinischen Hochschule Hannover", Germany, and found a proportion of 48 percent head injuries, of which 68 percent were located in the protection area of a helmet. Therefore, in this study it is assumed that a bicycle helmet is able to reduce substantially a fraction of $q_{\text {head }}=0,3264$ of all injuries. ${ }^{5}$

\footnotetext{
${ }^{4}$ Furthermore, in the HEAT algorithm, output depends also but only slightly on the number of cyclists.

${ }^{5}$ Hagel and Yanchar (2013) calculate a value of 20 percent to 40 percent of head injuries in bicycle injuries for Canada and Dinh et al. (2010) report that 25 percent of trauma admission registered in the Royal Prince Alfred Hospital, Sydney, Australia, had head injuries.
} 
TABle 1 - InPut Parameters AND sources

\begin{tabular}{|c|c|c|c|}
\hline Symbol & Description & value & Source \\
\hline$r r$ & Risk reduction by a helmet & 0.50 & Elvik (2013) \\
\hline$q_{\text {head }}$ & $\begin{array}{l}\text { Proportion of head injuries of all in- } \\
\text { juries }\end{array}$ & 0.3264 & Richter (2005) \\
\hline$V S L$ & Statistical value of life & $1,574,000 €$ & Kahlmeier et al. (2013) \\
\hline$S_{s}$ & Statistical value of severe injury & $0.13 \cdot V S L$ & ECMT (1998) \\
\hline$S_{m}$ & Statistical value of average injury & $0.027 \cdot V S L$ & own calculation \\
\hline$S_{l}$ & Statistical value of minor injury & $0.01 \cdot V S L$ & ECMT (1998) \\
\hline$c_{i}$ & $\begin{array}{l}\text { Fraction of statistical cost that are in- } \\
\text { ternalized }\end{array}$ & 0.6 & Elvik (1994) \\
\hline$F_{g}$ & Fatalities among cyclist (annual) & 406 & DeStatis (2013) \\
\hline$F_{s}$ & Severe injuries among cyclist (annual) & 13,854 & DeStatis (2013) \\
\hline$F_{l}$ & Minor injuries among cyclist (annual) & 60,516 & DeStatis (2013) \\
\hline$q_{h}$ & Proportion of cyclists using helmets & 0.13 & $\begin{array}{l}\text { Bundesanstalt für Straßen- } \\
\text { wesen (2013) }\end{array}$ \\
\hline$q_{i}$ & $\begin{array}{l}\text { Proportion of cyclists reporting regu- } \\
\text { lar use }\end{array}$ & 0.124 & Ritter and Vance (2011) \\
\hline$q_{g}$ & $\begin{array}{l}\text { Proportion of cyclists reporting occa- } \\
\text { sional use }\end{array}$ & 0.094 & Ritter and Vance (2011) \\
\hline$q_{n}$ & $\begin{array}{l}\text { Proportion of cyclists reporting no use } \\
\text { of a helmet }\end{array}$ & 0.782 & Ritter and Vance (2011) \\
\hline$C_{H}$ & Cost of a helmet & $27.62 €$ & own estimation \\
\hline$l_{H}$ & Time to replacement & 5 years & Recommendation Producer \\
\hline$B$ & Population of Germany & $82,218,000$ & $\begin{array}{l}\text { Bundesministerium } \quad \text { für } \\
\text { Verkehr (2012) }\end{array}$ \\
\hline$W$ & Distance cycled in Germany in 2008 & $3.2969410^{10} \mathrm{~km}$ & $\begin{array}{l}\text { Bundesministerium } \\
\text { Verkehr (2012) }\end{array}$ \\
\hline$w$ & Average distance cycled (annual) & $401 \mathrm{~km}$ & $\begin{array}{l}\text { Bundesministerium } \\
\text { Verkehr (2012) }\end{array}$ \\
\hline$r$ & Reduction of cycling & 0.044 & Carpenter and Stehr (2011) \\
\hline$v_{c}$ & Average speed motorized using car & $24.9 \mathrm{~km} / \mathrm{h}$ & Jahn and Krey (2010) \\
\hline$v_{b}$ & Average speed public transport & $17.0 \mathrm{~km} / \mathrm{h}$ & Jahn and Krey (2010) \\
\hline$v_{f}$ & Average speed of cycling & $12.30 \mathrm{~km} / \mathrm{h}$ & Jahn and Krey (2010) \\
\hline$v_{p}$ & Average speed of walking & $4.90 \mathrm{~km} / \mathrm{h}$ & Jahn and Krey (2010) \\
\hline$h_{p}$ & $\begin{array}{l}\text { Statistical value of health improve- } \\
\text { ment through walking per km (annual) }\end{array}$ & $\begin{array}{l}1.586171 \times 10^{-6} \\
V S L\end{array}$ & Kahlmeier et al. (2013) \\
\hline$h_{f}$ & $\begin{array}{l}\text { Statistical value of health improve- } \\
\text { ment through cycling per } \mathrm{km} \text { (annual) }\end{array}$ & $\begin{array}{l}6.676443 \times 10^{-7} \\
V S L\end{array}$ & Kahlmeier et al. (2013) \\
\hline$m s_{c}$ & Modal Split motorized using car & 0.31 & Jahn and Krey (2010) \\
\hline$m s_{b}$ & $\begin{array}{l}\text { Modal Split motorized public trans- } \\
\text { port }\end{array}$ & 0.26 & Jahn and Krey (2010) \\
\hline$m s_{p}$ & Modal Split walking & 0.30 & Jahn and Krey (2010) \\
\hline$c_{c}$ & External costs of a $\mathrm{km}$ driven by car & $0.0314 € €$ & Umweltbundesamt (2007) \\
\hline$r_{b}^{u}$ & $\begin{array}{l}\text { accidents with casualties per } 1 \text { Million } \\
\text { passenger-km public transport }\end{array}$ & 0.14 & DeStatis (2013) \\
\hline$r_{c}^{u}$ & $\begin{array}{l}\text { accidents with casualties per } 1 \text { Million } \\
\text { passenger-km car }\end{array}$ & 0.26 & DeStatis (2013) \\
\hline$r_{p}^{u}$ & $\begin{array}{l}\text { accidents with casualties per } 1 \text { Million } \\
\text { km walking }\end{array}$ & 0.92 & DeStatis (2013) \\
\hline$r_{f}^{u}$ & $\begin{array}{l}\text { accidents with casualties per } 1 \text { Million } \\
\mathrm{km} \text { cycling }\end{array}$ & 2.35 & DeStatis (2013) \\
\hline$r_{b}^{g}$ & $\begin{array}{l}\text { fatalities per } 100 \text { Million passenger-km } \\
\text { public transport }\end{array}$ & 0.02 & DeStatis (2013) \\
\hline$r_{c}^{g}$ & $\begin{array}{l}\text { fatalities per } 100 \text { Million passenger-km } \\
\text { car }\end{array}$ & 0.23 & DeStatis (2013) \\
\hline$r_{p}^{g}$ & fatalities per 100 Million $\mathrm{km}$ walking & 1.76 & DeStatis (2013) \\
\hline$r_{f}^{g}$ & fatalities per 100 Million $\mathrm{km}$ cycling & 1.22 & DeStatis (2013) \\
\hline
\end{tabular}


A meta-study by Attewell, Glase and McFadden (2001) notes that the risk of head injury is reduced by 60 percent by wearing a bicycle helmet, and in particular, the risk of brain injury by 58 percent and of facial injuries by 47 percent. The most comprehensive meta-study is by Elvik (2013), who concludes that bicycle helmets effectively reduce head injuries. In contrast, no (or a negative) neckinjury effect is observed. For the following calculations, the odds ratio calculated in a publication bias-adjusted meta-analysis (random effects model) of 23 studies by Elvik (2013) is used. He calculates an odds ratio of 0.5, with a 95 percent confidence interval of 0.39 to 0.65 . In this study, the concept of risk reduction is used and the assumed risk reduction value of $r r=0.5$ means that wearing a bicycle helmet reduces the severity of an injury in 50 percent of the accidents. ${ }^{6}$

The value of a statistical life is set to $V S L=1.574$ Million $€$ (Kahlmeier et al., 2013). The statistical cost of a severe injury (at least one day at the hospital) is set to $S_{s}=0.13 \cdot V S L$ and a minor injury to $S_{l}=0.01 \cdot V S L$ (European Conference of Ministers of Transport , ECMT) ${ }^{7}$ It is assumed that the positive effect of wearing a bicycle helmet is that there will be only a serious injury instead of a fatality, a minor injury instead of a serious injury and no injury instead of a minor injury. This assumption is used here because only head injuries are considered and because a bicycle helmet is a passive safety measure that does not prevent accidents but only reduces the severity of an injury.

When calculating the effect of helmet-wearing, using actual numbers of fatalities and injuries, we have to consider that the observed numbers are fatalities and injuries in the current (2012) population of helmet wearers and non-wearers. That means, for example, that some of the seriously injured helmeted cyclists of 2012 would have been fatalities if they had been unhelmeted. To calculate the hypothetical numbers $F_{g}^{h}, F_{s}^{h}$ and $F_{l}^{h}$ of victims in a completely helmet-free environment, we use the fact that risk reduction $r r$ only works for the fraction of head injuries $q_{\text {head }}$ of the proportion of $q_{h}$ helmeted cyclists and therefore only for a proportion $f=q_{h} \cdot q_{h e a d} \cdot r r=0.0212$, the accident severity is reduced from fatality to severe, severe to slight or slight to none.

$$
\begin{aligned}
F_{g} & =(1-f) F_{g}^{h} \\
F_{s} & =f F_{g}^{h}+(1-f) F_{s}^{h} \\
F_{l} & =f F_{s}^{h}+(1-f) F_{l}^{h}
\end{aligned}
$$

The system of equations are solved by

$$
\begin{aligned}
F_{g}^{h} & =\frac{F_{g}}{1-f} \\
F_{s}^{h} & =\frac{F_{s}-f\left(F_{g}+F_{s}\right)}{(1-f)^{2}} \\
F_{l}^{h} & =\frac{F_{l}(1-f)^{2}+f\left(f\left(F_{g}+F_{s}\right)-F_{s}\right)}{(1-f)^{3}}
\end{aligned}
$$

\footnotetext{
${ }^{6}$ The odds ratio is different from the relative risk and the odds ratio will always exaggerate the size of the effect, compared to a relative risk. Using the estimate of an odds ratio as risk reduction, as in this study, slightly overestimates the actual risk reduction of bicycle helmets.

${ }^{7}$ If there are only data about injuries, a weighted average of $S_{m}=0.027 \cdot V S L$ per injury is used.
} 
getting numbers of $F_{g}^{h}=414.8, F_{s}^{h}=14,145.3$ und $F_{l}^{h}=61,521.1$.

The statistical monetary value of reduced injury severity or fatalities resulting from the wearing of bicycle helmets can now be calculated. The value $N^{h}$ is hypothetical, because it compares a situation that all cyclists wearing a helmet to that of no cyclists at all wearing a helmet:

$$
N^{h}=(1-r r) q_{\text {head }}\left[\left(V S L-S_{s}\right) F_{g}^{h}+\left(S_{s}-S_{l}\right) F_{s}^{h}+S_{l} F_{l}^{h}\right]
$$

which is $N^{h}=686,766,000 €$. Using the fact that in Germany the annual distance cycled is $W=3.296942 \times 10^{10}$ (Bundesministerium für Verkehr, 2012), we can estimate a statistical value for the protection provided by a helmet to $V_{k m}^{h}=N^{h} / W=2.083$ Cent per $\mathrm{km}$ cycled. Remembering that the law induces $W_{\text {ind }}=\left(1-q_{h}\right) \cdot(1-r) \cdot W$ of helmeted cycling the benefit derived from this induced helmet use is

$$
N_{f}=V_{k m}^{h} \cdot W_{i n d}=N^{h}\left(1-q_{h}\right)(1-r)=571,197,000 €
$$

per year.

\section{B. The substitution of cycling: Impacts on health, exposure to risk and environment}

Cycling has a positive effect on health and increases life expectancy (de Hartog et al., 2010). Substituting the bicycle by other transport modes is thus expected to have negative health consequences. Following Kahlmeier et al. (2013) and using the algorithm HEAT provided on the webpage www.heatwalkingcycling.org by the WHO Regional Office for Europe, the statistical value of the health gains can be estimated to $h_{f}=6.676443 \times 10^{-7} \cdot V S L=1.05 €$ per additional km cycled and $h_{p}=1.586171 \times 10^{-6} \cdot V S L=2.50 €$ per additional $\mathrm{km}$ walked by a pedestrian. ${ }^{8}$ Using a bus or a car is not conducive to good health. The distance $W^{s}$ of cycling that is substituted therefore induces monetary costs of $h_{f} \cdot W^{s}$ and only the distance $W_{p}^{s}$ that is walked improves health by $h_{p} \cdot W_{p}^{s}$. The monetary losses due to deteriorating health are

$$
K_{h}=h_{f} \cdot W^{s}-h_{p} \cdot W_{p}^{s}
$$

i.e. $K_{h}=462,463,000 €$.

The former cyclists are also at some degree of risk when walking, driving or using public transport. The number of accidents with casualties (fatalities) per 1 Million (100 Million) passenger-km in 2011 (DeStatis, 2013) are $r_{B}^{u}=0,14$ $\left(r_{B}^{g}=0,02\right)$ if using public transport, $r_{C}^{u}=0,26\left(r_{C}^{g}=0,23\right)$ if driving a car ${ }^{9}$, $r_{P}^{u}=0,92\left(r_{P}^{g}=1,76\right)$ if walking and $r_{F}^{u}=2,35\left(r_{F}^{g}=1,22\right)$ if bicycling. (Not) using transport mode $i$ (reduces) induces costs of

$$
r c_{i}=r_{i}^{g} \cdot 10^{-8} \cdot V S L+r_{i}^{u} \cdot 10^{-6} \cdot S_{m}
$$

per kilometer. Because the distance $W^{s}$ of cycling is substituted by $W_{p}^{s}$ of walking,

\footnotetext{
${ }^{8}$ Input data for the algorithm are that $63,510,000$ million cyclists, that is, the unhelmeted 87 percent of $B_{f}=73,000,000$ cyclists in Germany, reduce cycling by $0.18840 \mathrm{~km}$ at 124 days and additional walk a distance of $8.0534 \mathrm{~km}$ annually, resulting in an annual reduction of cycling $W^{s}$ additional walking of $W_{p}^{s}$.

${ }^{9}$ Risk factors of cars may be biased by a large share of safe motorways.
} 
$W_{c}^{s}$ of traveling by car and $W_{b}^{s}$ of public transport, the benefit is

$$
N_{n}=r c_{F} \cdot W^{s}-r c_{p} W_{p}^{s}-r c_{c} W_{c}^{s}-r c_{b} W_{b}^{s}
$$

i.e. $N_{n}=119,904,000 €$.

From an environmental point of view, the substitution of cycling is undesirable. Traveling by car induces external costs (including Climate change, air pollution, soil sealing and noise) $c_{c}=0.0314 €$ per kilometer (Umweltbundesamt, 2007). Therefore, additional costs are $K_{e}=c_{c} \cdot W_{c}^{s}=11,226,200 €$ annually.

\section{Comfort losses}

Additional costs arise through the utility losses caused by helmet wear. Youths do not like wearing helmets, primarily because they are regarded as uncool (Stiftung Warentest, 2012). Helmets are also incompatible with "big hair" such as that of Marge Simpson. In addition, a helmet generally reduces air circulation. As the benefit components of a good helmet, Stiftung Warentest, the leading German consumer watchdog, rates accident prevention at 50 percent, handling and comfort (including effective air circulation to prevent increasing temperatures under the helmet) at 35 percent, heat resistance at 10 percent and pollutants at 5 percent. According to Ritter and Vance (2011), a share of $q_{g}=0.094$ of all cyclists uses a helmet occasionally. Assuming that these cyclists already own a helmet, they do not incur marginal acquisition costs, so that the only marginal costs are the comfort reduction when using, and the inconvenience of carrying around a helmet when not actually cycling. These cost vary, so that wearing the helmet is sometimes optimal and sometimes not. Assuming rational behavior ${ }^{10}$, the utility losses must exceed the gains derived from helmet protection. However, some of the protection effect of a helmet, for example hospital costs and part of productivity losses, are external to cyclists because they are covered by social insurance. Therefore, it is assumed that only a fraction $c_{i}=0.60$ of the benefits $V_{k m}^{h}$ are internalized (Elvik, 1994). Utility losses due to helmet wear are at least $c_{i} \cdot V_{k m}^{h}=0.0125 € / \mathrm{km}$ when a cyclist owning a helmet does not use it. ${ }^{11}$ It is assumed that average utility losses are $u l=0.00625 € / \mathrm{km}$. Furthermore, cyclists who never wear helmets in the status quo suffer a loss of comfort when forced to cycle helmeted. Arguably, they wear no helmet because their losses would be rather high and not because their travel distance or income is rather small. However, in this study, it is assumed that utility losses are $u l$ and a helmet law induces utility losses

$$
K_{g}=u l \cdot W_{i n d}=171,359,000 €
$$

per year.

\footnotetext{
${ }^{10}$ Börjesson and Eliasson (2012) find that cyclists generally take the health effects into account when making their choices.

${ }^{11}$ The occasional helmet user has utility losses that are smaller than $c_{i} V_{k m}^{h}$ when wearing a helmet and greater than $c_{i} V_{k m}^{h}$ when not wearing the helmet. Therefore, losses are greater than or equal to zero when wearing a helmet and greater than or equal to $c_{i} V_{k m}^{h}$ when not wearing a helmet. For cyclists not owning a helmet utility losses exceed the gains from helmet protection minus purchasing costs. To cover this range of lower bounds of rational utility losses, the interval $\left[0, c_{i} \cdot V_{k m}^{h}\right]$ is used in a sensitivity analysis (see Section 3.6) and $u l$ is defined as midpoint of the interval.
} 


\section{Costs of helmets}

Costs for helmets have to be taken into account. ${ }^{12}$ Costs arise from the fact that helmets must be produced and purchased. Stiftung Warentest (2012) collected retail price data and identified helmets of good quality. The cheapest good adult helmet costs $18 €$ and the cheapest good kids helmet $20 €$ (Stiftung Warentest, 2012). Cyclists are advised to buy from specialized dealers. $47.75 €$ is the average recommended retail price charged by specialized dealers for the twelve best-selling helmets sold by amazon.de December 12th, 2013. It is assumed for the present study that helmets can be purchased for $32.875 €$, which is the average of the cheapest helmet of good quality $(18 €)$ and the average recommended retail price $(47.75 €)$. In Germany, prices include a 19 percent sales tax, which is not a social cost, such that the opportunity costs of a helmet are $C_{H}=27.62 €$. All manufacturers recommend replacing helmets after $l_{H}=5$ years.

Up to now we calculated average values per kilometer cycled using data about the distance travelled by bicycle of all cyclist in Germany during a year. The average distance travelled, $401 \mathrm{~km}$, was used only to illustrate some results. However, to calculate the number of helmets cyclist have to buy to comply with a helmet law, we have to estimate the number of cyclist who do currently not own a helmet. In Germany there are about $B_{f}=73,000,000$ bicycles (DeStatis, 2013) which is used as number of cyclist, ignoring cyclists who own more than one bike and shared used of a bicycle (but not of a helmet). According to Ritter and Vance (2011), a fraction $q_{i}=0.124$ of German cyclists wear a helmet regularly and $q_{g}=0.094$ sometimes. Regular and occasional helmet users already own a helmet but all of those, who have never used a helmet, have to buy a new one. Therefore, costs of

$$
K_{m}=B_{f} \cdot\left(1-q_{i}-q_{g}\right) \cdot \frac{C_{H}}{l_{H}}
$$

i.e. $315,412,000 €$, arise.

\section{E. Benefit cost ratio}

As Figure 2 shows, most important is the protection effect $N_{f}$. This effect is about 25 percent higher than the (negative) health effect and therefore, a fully enforced bicycle helmet law is effective from a health perspective. However, the production costs of helmets $K_{m}$ amount to about half of the monetary value of the protection effect. There is a safety (Exposure) gain, due to the substitution of bicycle riding by less risky modes, which amounts to about a third of the helmet costs. However, from an environmental point of view, the substitution is not desirable. The welfare losses due to reduced comfort when cycling are calculated at about two thirds of the helmet costs. To summarize, we can calculate a benefitcost ratio of

$$
B C R=\frac{N_{f}+N_{n}}{K_{m}+K_{e}+K_{g}+K_{h}}=0.720 .
$$

A law that make the wearing of bicycle helmets in Germany mandatory is thus a waste of resources.

In reality, there are generally not only winners, but also losers from policies. The larger the benefit cost ratio, the easier it is to compensate the losers. Usu-

\footnotetext{
${ }^{12}$ Broadstock and Collins (2010) show that prices influence the demand for cycling to a greater extent than the income effects.
} 


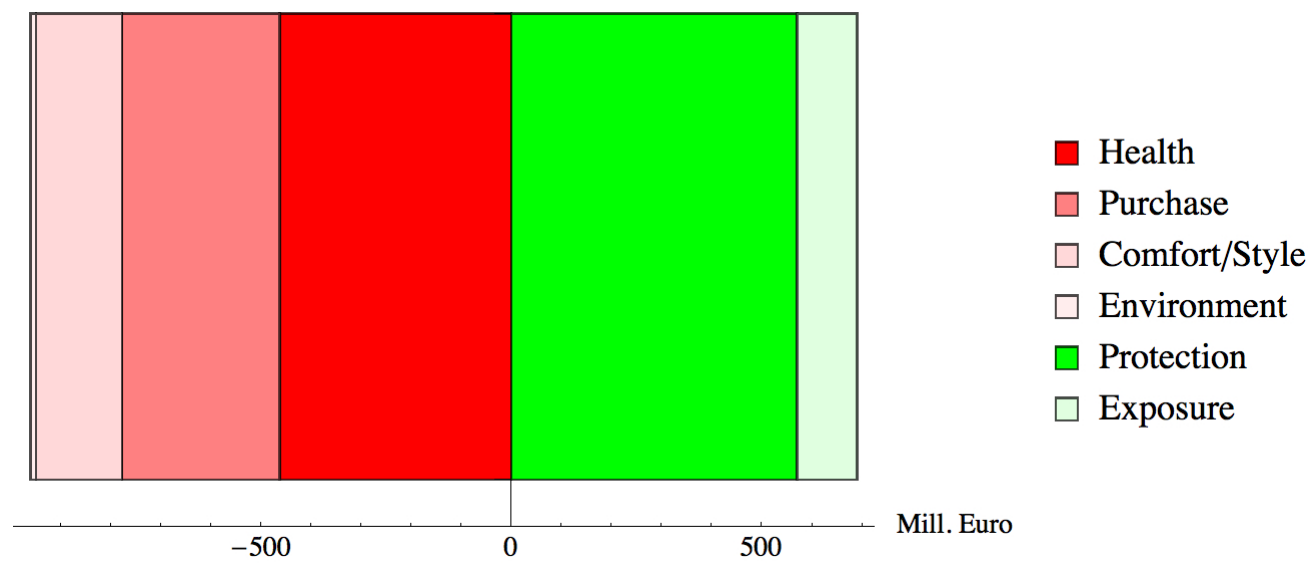

Figure 2. Annual costs (Red) And Benefits (Green) of a helmet law

ally, resources are scarce and only the most efficient policy measures are funded. Following a cost-benefit approach, the projects with the highest benefit cost ratio should be the first to be implemented. Cavill et al. (2008) find, in their review on the studies of economic valuation of transport infrastructure or policy, that included data on walking and/or cycling and health effects, a median benefit cost ratio of 5 . Compared to safety belts or bicycle brakes and lights, a helmet becomes part of a person's outfit and is therefore is very important for social communication. Governmental regulation of such a personal matter is justified, if at all, only if the benefit cost ratios are relatively large compared to those of other available policies .

\section{F. Sensitivity Analysis}

There is a range of plausible assumptions about the parameters used in this study that may change the benefit cost ratio. Therefore, additional calculations are made using, when possible, the boundaries of a 95 percent confidence interval of the used parameters. ${ }^{13}$ In Table 2, each cell includes a parameter value in the first row that leads, in combination with the other normal parameters, to the benefit cost ratio (BCR) displayed in the second row of the cell.

In only one of the scenarios is a benefit cost ratio slightly larger than 1 calculated. The reduction of cycling is the crucial factor in this study. If there is more than 1.25 percent reduction of cycling due to a helmet law then the BCR is less than $1 .{ }^{14}$ Isolated estimation errors of the risk-reduction effect of bicycle helmets, the proportion of head injuries of bicycle accidents, the value of a statistical life,

\footnotetext{
${ }^{13}$ Normal values are explained in Chapter 2 and 3. Low and high values for $r r$ are the boundaries of a 95 percent confidence interval (Elvik, 2013). qhead low and high values are from Hagel and Yanchar (2013). Following (Bickel et al., n.d., p. 87), the low value of VSL is $V S L / 3$ and the high value $V S L \cdot 3$. The low value of $C_{H}$ is the price net of sales taxes for the cheapest good adult helmet according to Stiftung Warentest (2012). The high value of $C_{H}$ is the average recommended retail price net of sales taxes for the twelve best-selling helmets sold by amazon.de December 12th, 2013. Low and high values for $r$ are the boundaries of a 95 percent confidence interval (see Footnote 2). The value $u l=0 €$ indicates that there are no losses due to Comfort or Style, the value of $u l=0.0125 €$ indicates that helmet owners who never wear the helmet in the status quo are rational in the sense that utility losses due to wear are at least as high as the expected (internal) benefits due to protection.

${ }^{14}$ Furthermore, the pure health effect (not including costs of helmets and environmental effects) gets negative if there is more than a 7.5 percent reduction of cycling.
} 
social costs of producing a helmet or the utility losses from using a helmet, do not alter the conclusion that a bicycle helmet law for Germany would waste resources.

TABLE 2 - SENSITIVITY ANALYSIS

\begin{tabular}{|c|c|c|c|c|}
\hline Parameter & low & normal & high & Description \\
\hline \multirow[t]{2}{*}{$r r$} & 0.39 & 0.50 & 0.65 & Risk reduction by a helmet \\
\hline & 0.816 & 0.720 & 0.574 & \\
\hline$q_{\text {head }}$ & 0.2 & 0.3264 & 0.4 & Proportion of head injuries \\
\hline $\mathrm{BCR}$ & 0.523 & 0.720 & 0.823 & \\
\hline$V S L$ & $524,667 €$ & $1,574,000 €$ & $4,722,000 €$ & Value of Statistical Life \\
\hline $\mathrm{BCR}$ & 0.428 & 0.720 & 0.931 & \\
\hline$C_{H}$ & $15.13 €$ & $27.63 €$ & $40.13 €$ & Social costs of a helmet \\
\hline $\mathrm{BCR}$ & 0.845 & 0.720 & 0.626 & \\
\hline$r$ & 0.002 & 0.044 & 0.085 & Reduction of cycling \\
\hline $\mathrm{BCR}$ & 1.162 & 0.720 & 0.558 & \\
\hline$u l$ & $0 €$ & $0.00625 €$ & $0.0125 €$ & Utility loss of a helmet \\
\hline $\mathrm{BCR}$ & 0.867 & 0.720 & 0.607 & \\
\hline
\end{tabular}

\section{Omitted effects}

There are further effects of a helmet law that are omitted in this study because there is only weak evidence that the effects are statistically significant different to zero and/or because the monetary values are small.

Since Peltzman (1976), it is evident that individuals compensate for risk reduction. For example, cyclists who are forced to wear a helmet may cycle faster (Adams and Hillman, 2001; Elvik, 2013), a change in driving behavior which reduces the positive effects of a helmet law. However, Fyhri, Bjørnskau and Backer-Grøndahl (2012) do not support a risk-compensation effect of helmets, in particular because the speeding behavior of the most affected "speed-happy" group is associated more with other types of equipment than bicycle helmets. It is not because of the helmet that these cyclists ride fast, they use all available equipment (including helmets), because they want to ride fast. Therefore, risk compensation that may decrease the positive effects of a helmet law is ignored in this study.

Bikers are heterogenous. The helmet-wearing rate is positively affected by household income, the number of children in the household and by having an urban place of residence, and the helmet-wearing rate of women is lower than that of men (Ritter and Vance, 2011). The present study does not account for cyclist heterogeneity beyond helmet use and ownership. In reality, however, cyclists also differ in terms of distance cycled (and many other factors, Pucher and Buehler (2010)). Arguably, cyclists who cycle in a more risky (reckless) manner already wear helmets more often than the average. Helmet-wearing type (regular, occasional, never) and risk are thus related and not independent. This is a reason why a helmet law may shift the cyclist population in favor of more risky cyclists by crowding out traditional cyclists (Li et al., 2013; Fyhri, Bjørnskau and Backer-Grøndahl, 2012). However, it is not easy to formulate a group-specific helmet law only for risky groups, because cyclists are often members of different groups. There is no reliable data on whether or not a $\mathrm{km}$ cycled by an experienced (thus probably low risk) mountain biker (high risk) is riskier than a $\mathrm{km}$ of a person who infrequently (high risk) cycles traditionally (low risk). Furthermore, the fewer cyclists on the road, the less car drivers will be aware of them. 
A helmet law then decreases the safety in numbers effect (Jacobsen, 2003). To address cyclist heterogeneity, traffic infrastructure, environment and other risk influencing factors a local group-specific cost-benefit analysis is appropriate, but due to a lack of reliable data, has rarely been conducted.

Helmet efficiency depends on several factors that differ in accidents. According to Richter (2005), the mean speed of collision for fatal accidents is $52.3 \mathrm{~km} / \mathrm{h}$, whereas the mean speed of collisions for non fatal is $20.8 \mathrm{~km} / \mathrm{h}$. In the event of an accident, a bicycle helmet works like "a crumple zone" by absorbing energy through the compression or fracture of the inner shell, which reduces brain acceleration. ${ }^{15}$ In Germany and in the European Union, helmets have to pass the norm EN 1078, which requires that at impact speeds of nearly $20 \mathrm{~km} / \mathrm{h}$, acceleration of the head be less than 250 times the gravity of earth $g$. Arguably, the ability of bicycle helmets to prevent fatalities is lower that of preventing injuries. Meehan et al. (2013) show that in accidents between bicycles and motor vehicles, the odds ratio of a helmet law for children younger than 16 for fatalities is 0.84 , with a 95 percent confidence interval of 0.70 to 0.98 . Therefore, the risk reduction rate in the current study may overestimate the impact of bicycle helmets on serious injuries and fatalities.

The effectiveness of a helmet is also influenced by how well it fits the head and the correct wearing position. However, Brian Walker (2005) of Head Protection Evaluation, Britain's principal helmet test lab, states: "Apart from racing cyclists, I rarely see a helmet that is worn properly." This study assumes that the helmet wearers forced to do so by law fit their helmet as well as (current) voluntary users. However, cyclists obliged to wear a helmet may wear them improperly and fail to replace them after 5 years as recommended. If this is true, the positive effect on safety of a helmet law is overestimated in the present study. At the same time, the annual purchase costs are lower than estimated.

Also not included in this study is the small negative effect of a bicycle helmet law on car congestion and the albeit modest costs of law enforcement which occur when the police spends time on helmet law enforcement that could be spend differently. Furthermore, it is assumed that the helmet law induces all cyclists to wear a helmet, which in reality will not be the case. However, when law breakers are only average cyclists who ignore the law, then only the costs and benefits of the law are reduced, but the cost benefit-ratio of the helmet law does not change.

\section{Conclusion}

For Germany, the benefits of a law that obliges cyclists to wear helmets are smaller than the costs. From an aggregated welfare point of view, Germany would therefore lose from introducing such a law. However, wearing a helmet when bicycling, does indeed reduce the negative consequences of accidents. A cyclist "earns" a value of 2.08 Cents of reduced costs for society per $\mathrm{km}$ of cycling by using a helmet. This is an argument in favor of wearing a helmet when cycling, but not for supporting a mandatory bicycle helmet law for Germany. Furthermore, policies that aim at increasing helmet use may have unwanted side effects. By emphasizing that biking without a helmet is careless, potential cyclists may conclude that cycling is intrinsically rather dangerous and thus decide not

\footnotetext{
${ }^{15}$ Curnow (2003) points out that the design of helmets is based on the theory that linear acceleration is the main cause of brain injury. Rotation of the head, which can even be increased by a helmet (Corner et al., 1987), is ignored.
} 
to cycle. Because cycling is in fact a safe (per travel time), healthy and environmentally friendly transport mode, (over-)emphasizing the risk of cycling (per distance) is not a prudent policy.

Nonetheless, increasing road safety is an important policy goal. To increase cyclists safety, stricter speed limits for cars, better monitoring of traffic rules combined with increased law enforcement, improving the cycling infrastructure, and generally encouraging cycling are sound policy options. Cost-benefit analyses of these different options should reveal which are efficient.

\section{REFERENCES}

Adams, John, and Mayer Hillman. 2001. "The risk compensation theory and bicycle helmets." Injury Prevention, 7: 89-91.

Attewell, Robyn G., K. Glase, and Michael McFadden. 2001. "Bicycle helmet efficacy: a meta-analysis." Accident Analysis and Prevention, 33: 345352.

Bickel, Peter, Rainer Friedrich, Arnaud Burgess, Patrizia Fagiani, Alistair Hunt, Gerard De Jong, James Laird, Christoph Lieb, Gunnar Lindberg, Peter Mackie, Stale Navrud, Thomas Odgaard, Andrea Ricci, Jeremy Shires, and Lori Tavasszy. "HEATCO - Developing Harmonised European Approaches for Transport Costing and Project Assessment Deliverable 5: Propposal for Harmonised Guidelines." http://heatco.ier.unistuttgart.de/HEATCO_D5.pdf, IER: Stuttgart.

Börjesson, Maria, and Jonas Eliasson. 2012. "The value of time and external benefits in bicycle appraisal." Transportation Research Part A: Policy and Practice, 46: 673-683.

Broadstock, David C., and Alan Collins. 2010. "Measuring unobserved prices using the structural time-series mode: The case of cycling." Transportation Research Part A: Policy and Practice, 44: 195-200.

Bundesanstalt für Straßenwesen. 2013. "Gurte, Kindersitze, Helme und Schutzkleidung - 2012." Forschung kompakt 6/13.

Bundesministerium für Verkehr, Bau und Stadtentwicklung, ed. 2012. Verkehr in Zahlen 2012/2013. DVV Media Group.

Carpenter, Christopher S., and Mark F. Stehr. 2011. "Intended and unintended consequences of youth bicycle helmet laws." Journal of Law and Economics, 54(2): 305-324.

Cavill, Nick, Sonja Kahlmeier, Harry Rutter, Francesca Racioppi, and Pekka Oja. 2008. "Economic analyses of transport infrastructure and policies including health effects related to cycling and walking: A systematic review." Transport Policy, 15: 291-304.

Corner, J. P., C. W. Whitney, N. O'Rourke, and D. E. Morgan. 1987. "Motorcycle and bicycle protective helmets: requirements resulting from a post crash study and experimental research." Federal Office of Road Safety Report CR 55 . 
Curnow, William J. 2003. "The efficacy of bicycle helmets against brain injury." Accident Analysis and Prevention, 35: 287-292.

de Hartog, Jeroen Johan, Hanna Boogaard, Hans Nijland, and Gerard Hoek. 2010. "Do the Health Benefits of Cycling outweigh the Risks?" Environmental Health Perspectives, 118(8).

de Jong, Piet. 2012. "The Health Impact of Mandatory Bicycle Helmet Laws." Risk Analysis, 32(5): 782-790.

DeStatis. 2013. "Fachserie 8 Reihe 7: Verkehr - Verkehrsunfälle 2012."

Dinh, Michael M, Susan Roncal, Timothy C. Green, Elizabeth Leonard, Amanda Stack, Chris Byrne, and Jeffrey Petchell. 2010. "Trends in head injuries and helmet use in cyclist at an inner-city major trauma centre, 1991-2010." Medical Journal of Australia, 193(10): 619-620.

Elvik, Rune. 1994. "The external costs of traffic injury: Definition, estimation and possibilities for Internalization." Accident Analysis and Prevention, 26(6): 719-732.

Elvik, Rune. 2013. "Erratum: Publication bias and time-trend bias in metaanalysis of bicycle helmet efficacy: A re-analysis of Attewell, Glase and McFadden, 2001 (Accident Analysis and Prevention (2011) 43 (1245-1251))." Accident Analysis and Prevention, 60: 245-253.

Elvik, Rune, Alena Høye, Truls Vaa, and Michael Sørensen. 2009. The Handbook of Rald Safety Measures, Second Edition. Bingley, UK:Emerald Group Publishing Limited.

European Conference of Ministers of Transport (ECMT), ed. 1998. Efficient Transport for Europe - Policies for Internalisation of External Costs. OECD Publications Service.

Fyhri, Aslak, Torkel Bjørnskau, and Agathe Backer-Grøndahl. 2012. "Bicycle helmets - A case of risk compensation?" Transportation Research Part F: Traffic Psychology and Behaviour, 15(5): 612-624.

Hagel, Brent E., and Natalie L. Yanchar. 2013. "Bicycle helmet use in Canada: The need for legislation to reduce the risk of head injury." Paediatr Child Health, 18(9): 475-480.

Jacobsen, Peter L. 2003. "Safety in numbers: More walkers and bicyclists, safer walking and bicycling." Injury Prevention, 9(3): 205-209.

Jahn, Helgard, and Joachim Krey. 2010. "Mobilität der Stadt - Berliner Verkehr in Zahlen." http://www.stadtentwicklung.berlin.de/verkehr/politik_planung/zahlen_fakten/ download/Mobilitaet_dt_komplett.pdf.

Kahlmeier, Sonja, Nick Cavill, Hywell Dinsdale, Harry Rutter, Thomas Götschi, Charlie Foster, Paul Kelly, Dushy Clarke, Pekka Oja, Richard Fordham, Dave Stone, and Francesca Racioppi. 2013. Health economic assessment tools (HEAT) for walking and for cycling. World Health Organization Regional Office for Europe. 
Li, Zhibin, Wei Wang, Chen Yang, and David R. Ragland. 2013. "Bicycle commuting market analysis using attitudinal market segmentation approach." Transportation Research Part A: Policy and Practice, 47: 56-68.

Meehan, William P., Lois K. Lee, Christopher M. Fischer, and Rebekah C. Mannix. 2013. "Bicycle helmet laws associated with a lower fatality rate from bicycle-motor vehicle collisions." Journal of Pediatrics, 163(3): 726729 .

Mokhtarian, Patricia L., and Cynthia Chen. 2004. "TTB or not TTB, that is the question: A review and Analysis of the empirical literature on travel time (and money) budgets." Transportation Research Part A: Policy and Practice, 38: 643-675.

Peltzman, Sam. 1976. "Toward a More General Theory of Regulation." The Journal of Law and Economics, 19(2): 211-240.

Pucher, John, and Ralph Buehler. 2010. "Walking and Cycling for Healthy Cities." Built Environment, 36(4): 391-414.

Richter, Martinus. 2005. "Verletzungen von Fahrradfahrern." Zeitschrift für Orthopädie und ihre Grenzgebiete, 143(6): 604-605.

Rissel, Chris, and Liming M. Wen. 2011. "The possible effect on frequency of cycling if mandatory bicycle helmet legislation was repealed in Sydney, Australia: A cross sectional survey." Health Promotion Journal of Australia, 22(3): 178-183.

Ritter, Nolan, and Colin Vance. 2011. "The determinants of bicycle helmet use: Evidence from Germany." Accident Analysis and Prevention, 43(1): 95100 .

Robinson, Dorothy L. 1996. "Head injuries and bicycle helmet laws." Accident Analysis and Prevention, 28: 463-475.

Robinson, Dorothy L. 2007. "Bicycle helmet legislation: Can we reach a consensus?" Accident Analysis and Prevention, 39(1): 86-93.

Sælensminde, Kjartan. 2004. "Cost-benefit analyses of walking and cycling track networks taking into account insecurity, health effects and external costs of motorized traffic." Transportation Research Part A: Policy and Practice, 38: 593-606.

Sager, Tore. 2013. "The Comprehensiveness Dilemma of Cost-Benefit Analysis." European Journal of Transport and Infrastructure Research, 13(3): 169-183.

Stiftung Warentest. 2012. "Coole Köpfe." test, 2012(5): 70-76.

Taylor, M, and Paul Scuffham. 2002. "New Zealand bicycle helmet law - do the costs outweigh the benefits?" Injury Prevention, 8: 317-320.

Umweltbundesamt. 2007. "Externe Kosten kennen - Umwelt besser schützen."

van Wee, Bert, and Piet Rietveld. 2013. "Using value of statistical life for the ex ante evaluation of transport policy options: a discussion based on ethical theory." Transportation, 40: 295-314.

Walker, Brian. 2005. "Heads up." Cycle, June/July: 42-45. 
Westfälische Wilhelms-Universität Münster, Institute of Transport Economics, Working Paper Series

12 "Specific Investments and Ownership Structures in Railways - An Experimental Analysis"

by Thomas Ehrmann/ Karl-Hans Hartwig/ Torsten Marner/ Hendrik Schmale, 2009

13 "Größenvorteile im deutschen ÖSPV - Eine empirische Analyse“ by Karl-Hans Hartwig/ Raimund Scheffler, 2009

14 "Measuring Efficiency of German Public Bus Transport“ by Raimund Scheffler/ Karl-Hans Hartwig/ Robert Malina, July 2010

15 „Market Power of Hub Airports: The Role of Lock-in Effects and Downstream Competition“

by Florian Allroggen/ Robert Malina, July 2010

16 "Studentische Automobilnutzung - mangels Alternativen?" by Daniel Krimphoff/ Peter Pollmeier, November 2011

17 „Ein Ansatz zur Verteilung der Bestellerentgelte im SPNV“ by Karl-Hans Hartwig/ Peter Pollmeier, September 2012

18 "Residential Parking in Vibrant City Districts" by Inga Molenda and Gernot Sieg, September 2013

19 "Are commercial ceilings adequate for the regulation of commercial overload on free-to-air TV channels?" by Julia Rothbauer and Gernot Sieg, September 2013

20 "Welfare Effects of Subsidizing a Dead-End Network of Less Polluting Vehicles"

by Antje-Mareike Dietrich and Gernot Sieg, October 2013

21 "Costs and benefits of a bicycle helmet law for Germany" by Gernot Sieg, March 2014

For a complete list of Working Papers published by Westfälische Wilhelms-Universität Münster, Institute of Transport Economics, please visit the website (http://www.ivmuenster.de) 
= 